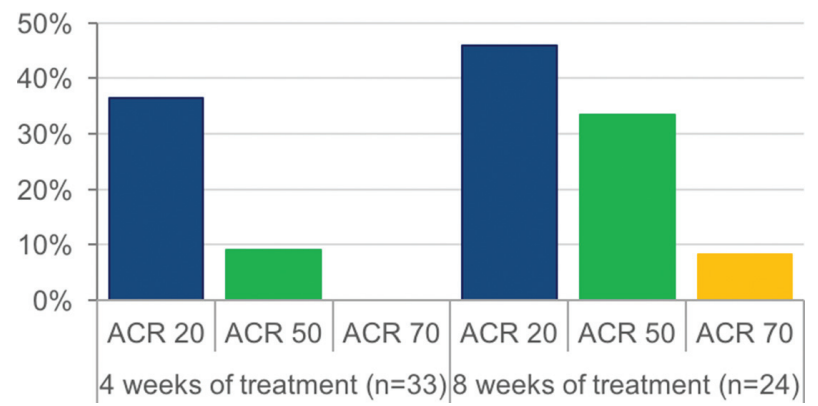

Abstract FRI0118 - Figure 1. ACR responses after 4 and after 8 weeks of Dekavil treatment in the phase 1 study population including all dose levels $(6-600 \mu \mathrm{g} / \mathrm{kg})$

Conclusions: The data obtained in the population studied to date suggest that Dekavil may be a safe and well tolerated novel therapeutic for the potential treatment of RA.

Disclosure of Interest: M. Galeazzi: None declared, G. Sebastiani: None declared, R. Voll: None declared, O. Viapiana: None declared, J. Dudler: None declared, P. Zufferey: None declared, E. Selvi: None declared, S. Finzel: None declared, F. Bootz Employee of: Philogen Group (Sponsor of the study), D. Neri Shareholder of: Philogen Group (Sponsor of the study)

DOI: 10.1136/annrheumdis-2018-eular.5550

\section{FRI0119 EFFECT OF DISCONTINUING TNF INHIBITORS DURING PREGNANCY ON THE COURSE OF RHEUMATOID ARTHRITIS AND JUVENILE IDIOPATHIC ARTHRITIS}

F. Förger ${ }^{1}$, G. Bandoli ${ }^{2}$, Y. Luo ${ }^{2}$, L. Robinson ${ }^{2}$, D.L. Johnson², C.D. Chambers ${ }^{2}$. ${ }^{1}$ Rheumatology, Immunology, Allergology, Inselspital UniversitäTsspital Bern, Bern, Switzerland; ${ }^{2}$ Department of Pediatrics, Medicine, and Family and Preventive Medicine, University of California San Diego, San Diego, USA

Background: Treatment changes at early pregnancy can be followed by a disease worsening. ${ }^{1}$

Objectives: To investigate whether the discontinuation of tumour necrosis factor inhibitors (TNFi) use during pregnancy is associated with any changes of disease activity at the third trimester in women with rheumatoid arthritis (RA) and juvenile idiopathic arthritis (JIA)

Methods: A prospective cohort study was conducted using the Organisation of Teratology Information Specialists (OTIS) Autoimmune Diseases in Pregnancy Project in the U.S. and Canada. Pregnant women with RA and JIA were enrolled between 2005 and 2017. Information about medication and disease activity were collected by telephone-based interviews prior to gestational week 20 and at gestational week 32. Disease activity was assessed by the Health Assessment Questionnaire Disability Index (HAQ-DI), the patient's pain scale and the patient's global scale. The composite tool Patient Activity Scale (PAS) was calculated in retrospect.

Results: In the OTIS cohort, data were available for 490 women of whom 397 had RA and 93 had JIA. Of all patients, $323(65.9 \%)$ used TNFi during pregnancy of whom $122(24.9 \%)$ patients discontinued TNFi before gestational week 20 (the mean time of discontinuation was gestational week $6(S D \pm 5.03))$ and 201 (41.0\%) used TNFi beyond week 20. There were 167 (34.1\%) patients not taking TNFi during pregnancy. At the time of enrollment, disease activity was low to minimal in $357(72.9 \%)$ patients as defined by PAS scores below 3.7 .

From the first to the third trimester, women using TNFi beyond week 20 showed a decrease of the PAS scores ( $p=0.02$, figure 1$)$ whereas women not using TNFi and those discontinuing TNFi before gestational week remained stable.

The univariate regression analysis, but not the adjusted model, revealed that TNFi use beyond week 20 was associated with improved HAQ scores at the third trimester (coefficient $\mathrm{B}-0.142,95 \% \mathrm{Cl}-0.258$ to -0.026 ) and with improved PAS scores (coefficient $\mathrm{B}-0.423,95 \% \mathrm{Cl}-0.843$ to -0.002 ). However, the various TNFi treatment modes during pregnancy were not associated with any minimum clinically important difference at the third trimester.

When selecting for 58 patients with active disease (PAS score $>3.71$ ) at the first trimester, the discontinuation of TNFi before gestational week 20 was not associated with any clinically important worsening of the disease at the third trimester.

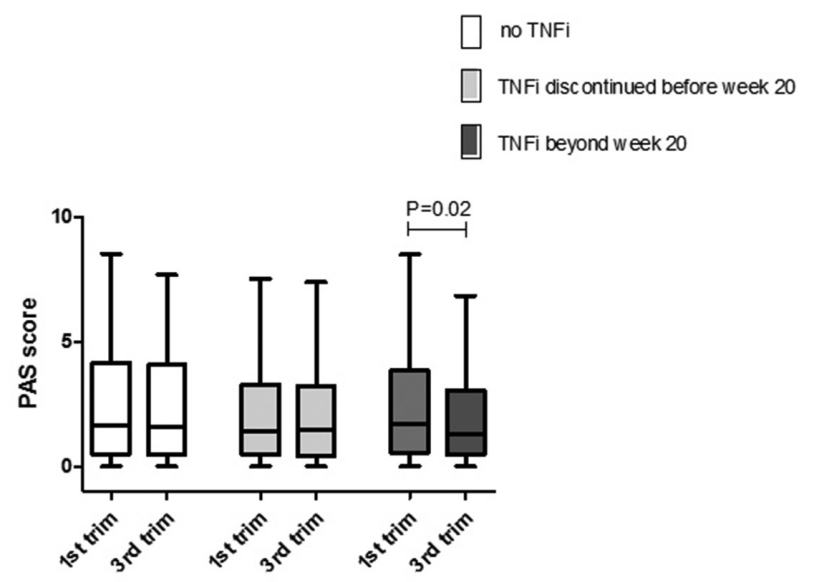

Conclusions: In patients with RA and JIA who enter pregnancy with well controlled disease, the discontinuation of TNFi before gestational week 20 is possible without a risk of disease flares at the third trimester.

\section{REFERENCE:}

[1] van den Brandt S, Zbinden A, Baeten D, Villiger PM, Ostensen M, Forger F. Risk factors for flare and treatment of disease flares during pregnancy in rheumatoid arthritis and axial spondyloarthritis patients. Arthritis research \& therapy. 2017;19(1):64.

Disclosure of Interest: None declared DOI: 10.1136/annrheumdis-2018-eular.5138

\section{FRI0120 EVALUATION OF RITUXIMAB, TOCILIZUMAB AND ABATACEPT IN A FRENCH MULTICENTER RHUPUS COHORT}

G. Laustriat ${ }^{1}$, O. Fogel ${ }^{2}$, D. Wendling ${ }^{3}$, S. Ottaviani ${ }^{4}$, S. Guignard ${ }^{5}$, J. Morel ${ }^{6}$, J. E. Gottenberg ${ }^{7}$ A. Cantagrel ${ }^{8}$, on behalf of CRI (Club Rhumatisme Inflammation). ${ }^{1}$ Rheumatology Department, Chu Toulouse Purpan, Toulouse; ${ }^{2}$ Hopital COCHIN, PARIS; ${ }^{3}$ Rheumatology Department, CHRU de Besançon, Besancon; ${ }^{4} A P-H P$, Hôpital Bichat-Claude Bernard, Service de Rhumatologie, Paris; ${ }^{5}$ Rheumatology Department, AP- HP, Hopital Henri Mondor, Creteil; ${ }^{6}$ Rheumatology Department, Chu Montpellier, Montpellier, ${ }^{7}$ Rheumatology Department, CHU Strasbourg, STRASBOURG: ${ }^{8}$ Chu Toulouse Purpan, Toulouse, France

Background: Rhupus, a combination of Rheumatoid Arthritis (RA) and Systemic Lupus Erythematosus, is a rare entity. Existing epidemiological and therapeutic data are limited.

Objectives: The aim of this study was to describe the therapeutic impact and safety of three biologic therapies: Rituximab, Tocilizumab and Abatacept in a french Rhupus cohort.

Methods: We have set up a transverse observational retrospective and multicentric study. To be included in the cohort, patients had to present an overlap syndrome fulfilling criterias for rheumatoid arthritis and lupus, and to be treated at least by one of these three therapies. Enrollment has been made with a file available on the CRI website and the analysis of the French RA registers (AIR, REGATE and ORA). Primary endpoint was the median time in therapeutic maintenance for each biological agent.

Results: Forty patients from fifteen rheumatologic centres were included. The main demographic data for these patients are given in table 1 . Thirty of them received a treatment with Rituximab, twelve with Tocilizumab and seven with Abatacept. Nine patients received 2 biologics at two different times of the disease. The medians of therapeutic maintenance were 82 months with Rituximab, 48 with Tocilizumab and 55 with Abatacept. The detailed analysis of clinical and biologic parameters revealed differences in effectiveness between therapies: corticosteroid doses decreased more in Rituximab group, VAS activity decreased more in Abatacept group, CRP decreased more in Tocilizumab group. Safety of biologics was similar to the data in literature for RA patients. 


\begin{tabular}{lccc}
\hline & $\begin{array}{c}\text { RITUXIMAB } \\
(\mathrm{n}=30)\end{array}$ & $\begin{array}{c}\text { TOCILIZUMAB } \\
(\mathrm{n}=12)\end{array}$ & $\begin{array}{c}\text { ABATACEPT } \\
(\mathrm{n}=7)\end{array}$ \\
\hline Disease duration (years) & 4.8 & 8.3 & 11.9 \\
Median of therapeutic & 82 & 48 & 55 \\
maintenance (month) & & & \\
Average duration of treatment & $44.8[5.8 ; 83.8]$ & $27.0[4.3 ; 49.7]$ & $26.0[-$ \\
(month) & & & $0.79 ; 52.93]$ \\
DAS 28 CRP evolution & $-1.03[-$ & $-1.88[-$ & $-1.97[-$ \\
& $2.73 ; 0.67]$ & $3.36 ;-0.38]$ & $3.55 ;-0.41]$ \\
Prednisone evolution (mg/d) & $-8.45[-$ & $-5.15[-$ & $-2.71[-$ \\
& $23.15 ; 9.25]$ & $10.95 ; 0.65]$ & $5.00 ;-0.43]$ \\
VAS evolution (/100) & $-5.40[-$ & $-18.50[-$ & $-30.43[-$ \\
& $32.70 ; 21.90]$ & $3.53 ; 35.04]$ & $65.27 ; 4.41]$ \\
CRP evolution (mg/L) & $-14.46[-$ & $-21.75[-$ & $-12.86[-$ \\
& $46.46 ; 17.54]$ & $53.41 ; 9.91]$ & $25.95 ; 0.26]$ \\
\hline
\end{tabular}

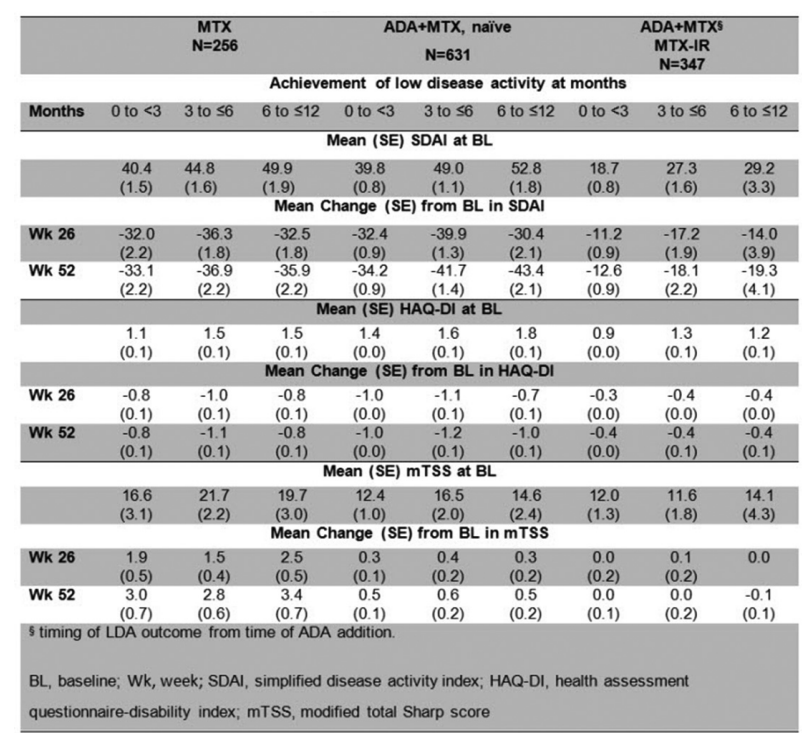

Conclusions: Pts on ADA+MTX achieved a first SDAI LDA response earlier than pts on MTX monotherapy, regardless of whether they were MTX-naïve or MTX IR. More pts with a very early response went on to achieve SDAI REM at 1 year. However, pts with a longer time (>6 mths) to their first SDAI LDA response had comparable clinical, functional and radiographic outcomes compared to pts who responded earlier (within 3 or 6 mths). Therefore, achieving a clinical response in the direction of the treatment target, even if not yet achieving it, may be sufficient to continue therapy in appropriate pts.

\section{REFERENCES:}

[1] Breedveld, et al. Arthritis \& Rheum 2006;54:26.

[2] Smolen, et al. Lancet 2014;383:321. mendations call for adjustment of treatment if a target is not met within months of initiation. While some pts continue therapy beyond 3-6 months despite not achieving the target, it's unclear if they still can achieve the target, and how the timing of target attainment impacts long-term outcomes.

Objectives: To evaluate clinical, functional, and radiographic outcomes on the basis of initial time to low disease activity (LDA) attainment among early RA pts who are naïve to MTX, or are MTX-insufficient responders (MTX-IR).

Methods: This post hoc analysis included pts receiving MTX in monotherapy or in combination with adalimumab (ADA) in 2 randomised, controlled trials (RCTs) of MTX-naïve pts with early RA: PREMIER included a 104 week (wk) $\mathrm{RCT}^{1}$; OPTIMA included a 26 wk RCT followed by treatment adjustments based on a target of LDA at wks 22 and $26^{2}$. Pts not achieving stable LDA received open-label (OL) ADA +MTX for an additional 52 wks (MTX-inadequate responders, IR). Pts were subgrouped by treatment and time to first LDA event [SDAI $\leq 11: 0-<3$ months (mths), $3-\leq 6 \mathrm{mths},>6-\leq 12 \mathrm{mths}]$. The following were summarised for each subgroup: mean values and change from baseline in SDAI, HAQ-DI and modified total Sharp score (mTSS). The proportions of pts achieving SDAI remission (REM) at 1 year (yr) were assessed.

Results: Roughly equal proportions of pts on MTX alone experienced their first LDA response between $0-<3$ mths (21\%), $3-\leq 6$ mths $(21 \%)$, and $>6-\leq 12$ mths (17\%). More pts on ADA+MTX experienced LDA within 3 mth $(0-<3: 45 \%$ and $56 \%$ for MTX-naïve and MTX-IR backgrounds, respectively), with smaller proportions in the $3-\leq 6$ mths (19\% for both MTX-naïve and -IR backgrounds), and $>6-\leq$ 12 mths groups (14\% and $4 \%$ for MTX-naïve and MTX-IR backgrounds). Approximately $50 \%$ of the $0-<3$ mth group across treatments achieved SDAI REM at 1 year. Interestingly, $10 \%, 14 \%$, and $8 \%$ of the MTX, ADA+MTX (MTX-naïve), and ADA+MTX (MTX-IR) pts who first experienced LDA after $6 \mathrm{mths}$ were in SDAI REM at 1 year.

Among MTX-naïve pts, pts on $\mathrm{ADA}+\mathrm{MTX}$ had greater $\triangle \mathrm{HAQ}$ and smaller $\Delta$ mTSS than pts on MTX alone at Wks 26 and 52 (table 1). Regardless of their time to first SDAI LDA response, pts on MTX monotherapy or ADA+MTX experienced comparable improvements in SDAI, HAQ-DI and comparable $\triangle \mathrm{mTSS}$ at Wks 26 and 52 .

Table 1 Mean Values at Baseline and Change From Baseline in Clinical, Functional, and Structural Parameters in Patients with Early RA Receiving MTX or ADA+MTX, on the Basis of First Achievement of Low Disease Activity by SDAI.
Acknowledgements: AbbVie: study sponsor, contributed to design, data collection, analysis, interpretation; and writing, reviewing, approval of final version. Medical writing: Naina Barretto of AbbVie.

Disclosure of Interest: J. Smolen Grant/research support from: AbbVie, Consultant for: AbbVie, X. Bu Shareholder of: AbbVie, Employee of: AbbVie, X. Wang Shareholder of: AbbVie, Employee of: AbbVie, J. Suboticki Shareholder of: AbbVie, Employee of: AbbVie, A. Kavanaugh Grant/research support from: AbbVie Inc., Amgen, Astra-Zeneca, BMS, Celgene, Centocor-Janssen, Pfizer, Roche, and UCB., Consultant for: expert advice to AbbVie Inc., Amgen, Astra-Zeneca, BMS, Celgene, Centocor-Janssen, Pfizer, Roche, and UCB

DOI: 10.1136/annrheumdis-2018-eular.2635

\section{FRI0122 DRUG SURVIVAL OF ADALIMUMAB IN PATIENTS WITH RHEUMATOID ARTHRITIS, ANKYLOSING SPONDYLITIS AND PSORIATIC ARTHRITIS OVER 10 YEARS IN REAL- WORLD SETTING OF CZECH REGISTRY ATTRA} Praha 2; ${ }^{2}$ Institute of Biostatistics and Analyses, Ltd., Spin-off company of the Masaryk University; ${ }^{3}$ Institute of Biostatistics and Analyses, Ltd., Masaryk University, Brno, Czech Republic

Background: Drug survival in real clinical practice is reflecting both efficacy and safety of the drug. It is valuable outcome measure complementary to data from RCT.

Objectives: To evaluate 10 years efficacy and survival of adalimumab (ADA) in Czech registry ATTRA. To analyse reasons for drug discontinuation and analyse baseline demographic and clinical characteristics predictive for drug discontinuation. We also aimed to compare survival of ADA between 3 different diagnosis (RA, AS, SpA). Finally we aimed to compare survival between different anti TNF drugs.

Methods: All patients fulfilled criteria of Czech Rheum. Soc. for indication of anti TNF therapy and were included in registry. They were followed each 3 month first
K. Pavelka ${ }^{1}$, J. Zavada ${ }^{1}$, Z. Kristkova ${ }^{2}$, L. Szczukova ${ }^{3} .{ }^{1}$ Institute of Rheumatology, 